\title{
Darbepoetin-a increases the blood volume flow in transplanted pancreatic islets in mice
}

\author{
Maximilian M. Menger ${ }^{1} \cdot$ Lisa Nalbach ${ }^{1}$. Selina Wrublewsky ${ }^{1}$. Matthias Glanemann ${ }^{2} \cdot$ Yuan $_{\text {Gu}}{ }^{1}$. \\ Matthias W. Laschke ${ }^{1} \cdot$ Michael D. Menger ${ }^{1} \cdot$ Emmanuel Ampofo $^{1}$ (])
}

Received: 12 November 2019 / Accepted: 4 March 2020 / Published online: 28 March 2020

(c) The Author(s) 2020, corrected publication 2021

\begin{abstract}
Aims The minimal-invasive transplantation of pancreatic islets is a promising approach to treat diabetes mellitus type 1 . However, islet transplantation is still hampered by the insufficient process of graft revascularization, leading to a poor clinical outcome. Accordingly, the identification of novel compounds, which accelerate and improve the revascularization of transplanted islets, is of great clinical interest. Previous studies have shown that darbepoetin (DPO)- $\alpha$, a long lasting analogue of erythropoietin, is capable of promoting angiogenesis. Hence, we investigated in this study whether DPO improves the revascularization of transplanted islets.

Methods Islets were isolated from green fluorescent protein-positive FVB/N donor mice and transplanted into dorsal skinfold chambers of FVB/N wild-type animals, which were treated with DPO low dose $(2.5 \mu \mathrm{g} / \mathrm{kg})$, DPO high dose $(10 \mu \mathrm{g} / \mathrm{kg})$ or vehicle (control). The revascularization was assessed by repetitive intravital fluorescence microscopy over an observation period of 14 days. Subsequently, the cellular composition of the grafts was analyzed by immunohistochemistry.

Results The present study shows that neither low- nor high-dose DPO treatment accelerates the revascularization of free pancreatic islet grafts. However, high-dose DPO treatment increased the blood volume flow of the transplanted islet.

Conclusions These findings demonstrated that DPO treatment does not affect the revascularization of transplanted islets. However, the glycoprotein increases the blood volume flow of the grafts, which results in an improved microvascular function and may facilitate successful transplantation.
\end{abstract}

Keywords Darbepoetin- $\alpha \cdot$ Islets $\cdot$ Transplantation $\cdot$ Revascularization $\cdot$ Diabetes $\cdot$ Angiogenesis $\cdot$ Endothelial cells

\section{Introduction}

Islet transplantation is a promising treatment strategy for the treatment of diabetes mellitus type 1, especially for patients suffering from glycemic instability and severe hypoglycemic episodes [1]. However, the reduced engraftment, which is caused by the delay of revascularization of the islets during the first few days after transplantation, is still a major

Managed by Massimo Federici.

Emmanuel Ampofo

emmanuel.ampofo@uks.eu

1 Institute for Clinical and Experimental Surgery, Saarland University, 66421 Homburg, Saar, Germany

2 Department for General, Visceral, Vascular and Pediatric Surgery, Saarland University, 66421 Homburg, Saar, Germany problem of this therapeutic approach [2]. Therefore, multiple donor organs are required for one recipient to achieve a longterm insulin independency [3].

We have recently shown that pretreatment of mice with EPO significantly accelerates the revascularization of transplanted islets. However, in clinical practice there is little time between receiving the appropriate donor pancreas and the transplantation itself. Therefore, an adequate pretreatment of patients with EPO might not be possible under clinical conditions. EPO treatment starting on the day of transplantation, however, showed only little effect in improving revascularization of freely transplanted islets [4]. This reduced effect might be due to the fact that the generation of a suitable plasma level of EPO requires several days.

A promising approach to overcome this problem may be the treatment of mice with darbepoetin (DPO)- $\alpha$ starting from the day of transplantation. This glycoprotein differs in its amino acid sequence and its carbohydrate content when 
compared with EPO [5]. Of note, the half-life of DPO is 2-3 times longer and the clearance approximately 4 times slower than those of EPO, which results in a higher bioavailability $[6,7]$. Besides its hematopoietic function, DPO exerts anti-apoptotic, anti-inflammatory and cytoprotective actions $[8,9]$. Moreover, DPO is capable of triggering angiogenic processes in vitro and in vivo $[10,11]$.

Based on these findings, we hypothesized that DPO treatment, starting from the day of transplantation, could be superior to EPO to ameliorate the revascularization process of transplanted islets. To prove this, islets were isolated from green fluorescent protein (GFP)-positive FVB/N donor mice and transplanted into dorsal skinfold chambers of recipient animals, which were treated with DPO low-dose, DPO high-dose or vehicle. The revascularization of the grafts was analyzed by means of repetitive intravital fluorescence microscopy and immunohistochemistry.

\section{Materials and methods}

\section{Reagents and antibodies}

Collagenase NB 4G was purchased from SERVA Elektrophoresis GmbH (Heidelberg, Germany). Fluorescein isothiocyanate (FITC)-dextran 150,000, rhodamine 6G and Hoechst 33,342 were purchased from Sigma-Aldrich (Taufkirchen, Germany), ketamine (Ursotamin ()) was purchased from Serumwerke Bernburg (Bernburg, Germany) and xylazine (Rompun ${ }^{\circledR}$ ) was purchased from Bayer (Leverkusen, Germany). HepatoQuick ${ }^{\circledR}$ and DPO- $\alpha$ (Aranesp $\left.{ }^{\circledR}\right)$ were purchased from Amgen (München, Germany). The antibody anti-CD31 (DIA310) was received from Dianova (Germany), the antibodies anti-insulin and the anti-myeloperoxidase (MPO) antibody (ab9535) from Abcam (Cambridge, UK), the antibody anti-GFP from Rockland Immunochemical Inc. (Limerick, USA) and anti-Casp-3 antibody from New England Biolabs (Frankfurt am Main, Germany).

\section{Animals}

FVB/N-TgN (Tie2/GFP) 287 Sato mice (Institute for Clinical and Experimental Surgery, Homburg/Saar, Germany) at the age of 12-24 weeks and a body weight of 25-30 g were used as donors for islet isolation. $\mathrm{FVB} / \mathrm{N}$ mice at the age of 8-10 weeks and a body weight of $22-27 \mathrm{~g}$ served as recipients for islet transplantation. The mice were housed one per cage under a 12/12 h day/night cycle and had free access to water and standard pellet chow (Altromin, Lage, Germany).

All experiments were performed according to the German legislation on protection of animals and the National Institutes of Health (NIH) Guide for the Care and Use of Laboratory Animals (Institute of Laboratory Animal Resources,
National Research Council, Washington DC, USA). The local governmental animal protection committee approved them (permission number: 58/2015).

\section{Isolation of pancreatic islets}

Mice were anesthetized by intraperitoneal (i.p.) injection of ketamine ( $75 \mathrm{mg} / \mathrm{kg}$ body weight) and xylazine $(25 \mathrm{mg} / \mathrm{kg}$ body weight). After a midline laparotomy, the pancreatic duct was identified and injected with $1 \mathrm{mg} / \mathrm{mL}$ collagenase solution containing $25 \mu \mathrm{L} / \mathrm{mL}$ neutral red. Subsequently, pancreatic islets were isolated as described previously in detail [12].

\section{Preparation of the dorsal skinfold chamber}

We used the dorsal skinfold chamber model (Fig. 1a) to analyze the revascularization of transplanted islets in vivo. The chamber implantation was performed as described previously in detail [13]. Briefly, the mice were anesthetized and two symmetrical titanium frames were implanted on the extended dorsal skinfold of the animals. Skin, subcutis and retractor muscle from the front side were completely removed in a circular area of $15 \mathrm{~mm}$. The remaining layers, consisting of muscle, subcutis and cutis of the back side, were covered by a removable cover glass, providing direct microscopic access to the microcirculation of the chamber. After the procedure, the animals were allowed to recover for $72 \mathrm{~h}$.

\section{Transplantation of pancreatic islets}

For the transplantation of pancreatic islets, the cover glass was removed, the chamber was washed twice with saline, and 6-8 freshly isolated neutral red-stained islets were transplanted onto the striated muscle tissue. Then, the chamber was sealed with a new cover glass (Fig. 1b).

\section{Intravital fluorescence microscopy}

Anesthetized mice were fixed on a plexiglas stage and received a retrobulbary, intravenous injection of $0.05 \mathrm{~mL}$ 5\% FITC-dextran 150.000 for contrast enhancement by staining of blood plasma. Moreover, $0.05 \mathrm{~mL} 2 \%$ rhodamine $6 \mathrm{G}$, which accumulates in endocrine but not in striated muscle tissue by extravasation from fenestrated endothelium, was intravenously given for the visualization of the rhodamine uptake and, by this, the determination of the endocrine revascularization, i.e. the ratio between the area of rhodamine uptake and the initial islet size [14]. Then, the dorsal skinfold chamber was positioned under a Zeiss microscope (Zeiss, Oberkochen, Germany) with a $100 \mathrm{~W}$ mercury lamp attached to a blue (excitation 


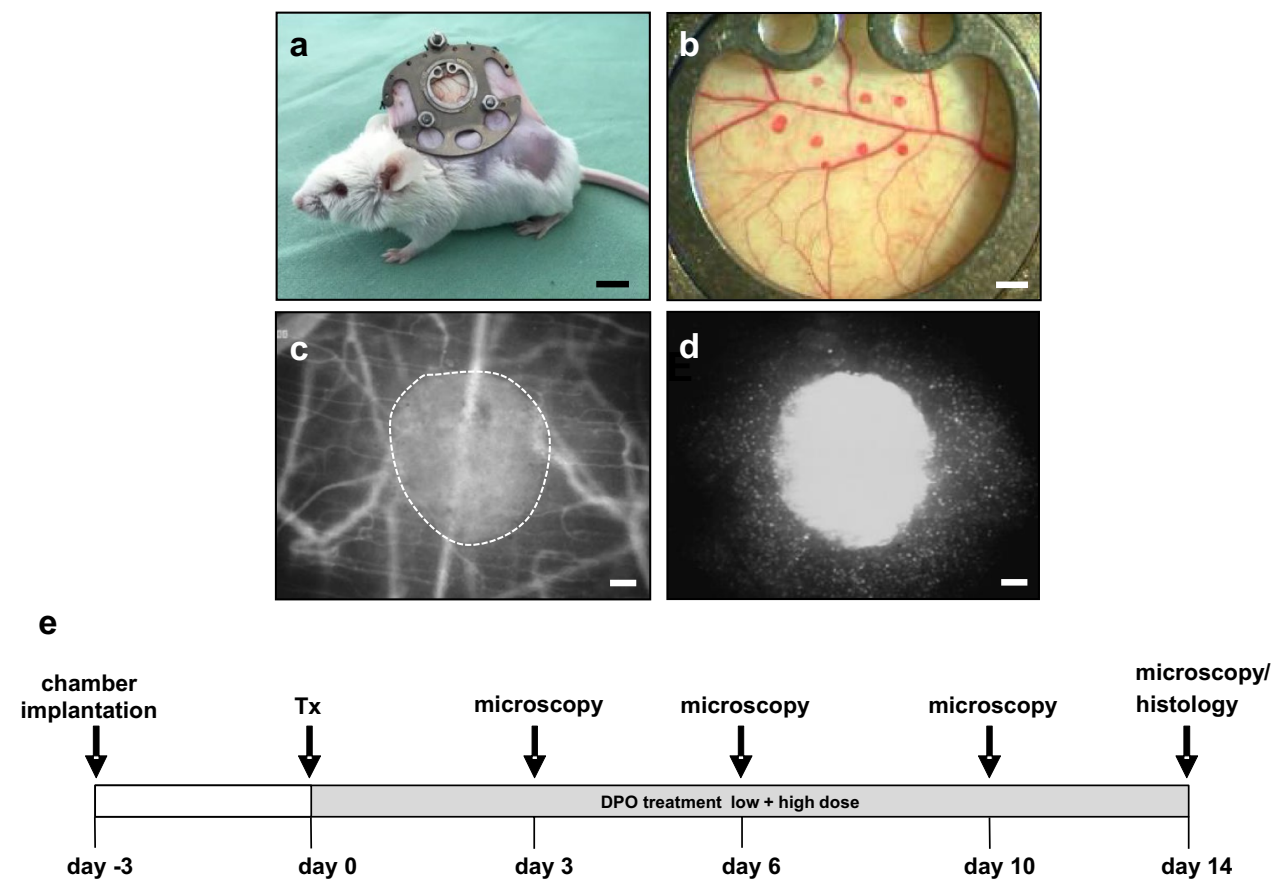

Fig. 1 Experimental setting of islet transplantation. a FVB/N mouse equipped with a dorsal skinfold chamber. Scale bar: $10 \mathrm{~mm}$. b Observation window of a dorsal skinfold chamber containing eight transplanted islets. Scale bar: $100 \mu \mathrm{m}$. c, d Intravital fluorescence microscopic images of a neutral red-stained islet within the dorsal skinfold chamber of a vehicle-treated animal on day 0 . The plasma marker FITC-dextran was used for the visualization of blood-per-

wavelength: $450-490 \mathrm{~nm} /$ emission wavelength: $>515 \mathrm{~nm}$ ) and a green $(530-560 \mathrm{~nm} />585 \mathrm{~nm})$ filter block. The microscopic images were recorded by a charge-coupled device video camera (FK6990; Pieper, Schwerte, Germany) and transferred to a monitor (Trinitron; Sony, Tokyo, Japan) and DVD system (DVD-HR775; Samsung, Eschborn, Germany) for off-line evaluation.

Quantitative analysis of the microscopic images was performed by the computer-assisted image analysis system CapImage (Zeintl, Heidelberg, Germany) and included the determination of the grafts' initial size $\left(\mathrm{mm}^{2}\right)$ (Fig. 1c, d), relative size of the vasculare network, i.e. the ratio between the revascularized area and the initial islet size, functional capillary density $\left(\mathrm{cm} / \mathrm{cm}^{2}\right)$ and endocrine revascularization as previously described $[15,16]$. We further measured microhemodynamic parameters, i.e. diameter $(\mu \mathrm{m})$, centerline red blood cell (RBC) velocity $(\mu \mathrm{m} / \mathrm{s})$ and volumetric blood flow ( $\mathrm{pL} / \mathrm{s}$ ), of individual microvessels within the grafts $[15,16]$. Moreover, we determined the take rate $(\%)$ on day 14 , i.e. the fraction of engrafted islets in relation to the number of transplanted islets. The successful engraftment was assessed by the presence of a newly formed islet-associated blood vessel network on day 14 . fused microvessels surrounding the islet (marked by dotted line) in blue light epi-illumination (c). The initial islet size was determined by neutral red-fluorescence in green light epi-illumination (d). Scale bar: $50 \mu \mathrm{m}$. e Schematic illustration of the experimental setting of DPO administration and islet transplantation. Recipient animals received DPO low dose, DPO high dose or vehicle every 3 days starting from the day of transplantation (day 0 )

\section{Experimental protocol}

Seven FVB/N-TgN (Tie2/GFP) 287 Sato mice were used as donors for pancreatic islet transplantation. A total number of $27 \mathrm{FVB} / \mathrm{N}$ mice were equipped with dorsal skinfold chambers. The mice were randomly assigned to 3 experimental groups of 9 animals each. DPO low dose $(2.5 \mu \mathrm{g} / \mathrm{kg}$ body weight, i.p.), DPO high dose $(10 \mu \mathrm{g} / \mathrm{kg}$ body weight, i.p.) and vehicle (ctrl; $100 \mu \mathrm{L}$ saline, i.p.) was administrated every 3 days, starting from the day of transplantation (day 0). Repetitive intravital fluorescence microscopy was performed on days $0,3,6,10$ and 14 after transplantation. At the end of the experiments, blood samples were drawn from the vena cava and the hematocrit levels, hemoglobin, the number of RBC, neutrophilic granulocytes and monocytes were determined by a hematology analyzer (Abaxis VetScan HM5; scil animal care company GmbH, Viernheim, Germany). Subsequently, the islet-containing chamber tissue was excised for further histological and immunohistochemical analyses (Fig. 1e). 


\section{Histology and immunohistochemistry}

For the preparation of histological sections, specimens of islet-containing dorsal skinfold chamber preparations were fixed for $24 \mathrm{~h}$ in $4 \%$ formalin. In addition, freshly isolated islets were incubated for $45 \mathrm{~min}$ at $37^{\circ} \mathrm{C}$ in $100 \mu \mathrm{L}$ HepatoQuick ${ }^{\circ}, 50 \mu \mathrm{L}$ human citrate plasma and $10 \mu \mathrm{L} 10 \% \mathrm{CaCl}_{2}$ solution. The resulting clot was also fixed for $24 \mathrm{~h}$ in $4 \%$ formalin. The formalin-fixed specimens were then embedded in paraffin and $3-\mu \mathrm{m}$-thick sections were cut.

The sections were stained with hematoxylin and eosin (HE) according to standard procedures. For the immunohistochemical analysis, the sections were stained with an anti-insulin, anti-GFP, anti-CD31 and anti-MPO antibody, which were detected by their corresponding secondary antibodies. Cell nuclei were stained with Hoechst 33,342. The sections were analyzed by means of fluorescence microscopy (BX60F; Olympus, Hamburg, Germany). The numbers of insulin-positive, CD31- and GFP-positive islet cells were counted using ImageJ software (NIH, Bethesda, MD, USA) and given in $\%$ of all islet cells.

\section{Statistical analysis}

After testing the data for normal distribution and equal variance, differences between the groups were assessed by the one-way analysis of variance (One-way ANOVA). To test for time effects within individual groups, ANOVA on ranks for repeated measures was applied. This was followed by the Student-Newman-Keuls post-hoc test (SigmaPlot 13.0; Jandel Corporation, San Rafael, CA, USA). All values are expressed as mean \pm SEM. Statistical significance was accepted for $P<0.05$.

\section{Results}

\section{Effect of DPO treatment on the revascularization of the islet grafts}

The size of the transplanted islets varied between 0.11 and $0.14 \mathrm{~mm}^{2}$, but did not differ significantly between the three experimental groups. First, we analyzed the transplanted islet functional capillary density of vehicle-, DPO low-doseand DPO high-dose-treated animals over the 14-day period. We found a significant increase of the functional capillary density from day 0 to day 6 and to day 10 , however, without a significant difference between the three study groups (Fig. 2a, b). The relative size of the vascular network was also not affected by the treatment with the glycoprotein when compared to animals receiving only vehicle (Fig. 2a, c).

Next, we measured the endocrine revascularization of the islets, which can be assessed by the accumulation of

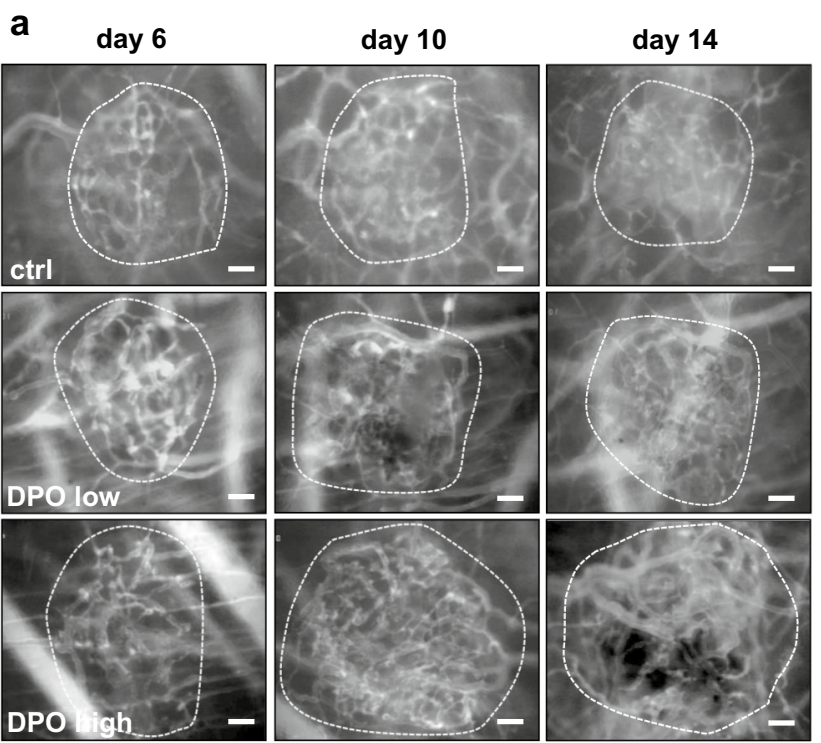

b

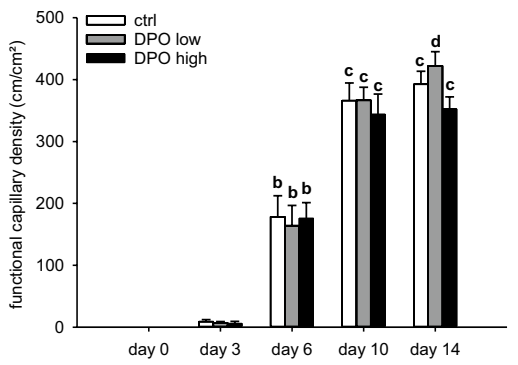

C

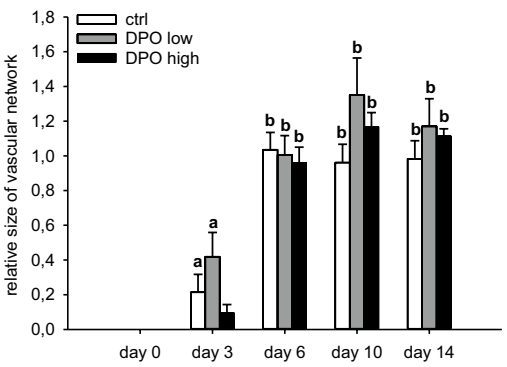

Fig. 2 Effect of DPO treatment on the revascularization of transplanted islets. a Representative intravital microscopic images of islets (marked by dotted lines) on days 6,10 and 14 after transplantation into the dorsal skinfold chamber of $\mathrm{FVB} / \mathrm{N}$ mice, which were treated with vehicle (ctrl), DPO low dose or DPO high dose. The plasma marker FITC-dextran was used for the visualization of microvessels in blue light epi-illumination. Scale bar: $50 \mu \mathrm{m}$. b, c Functional capillary density $\left(\mathrm{cm} / \mathrm{cm}^{2}\right)(\mathbf{b})$ and the relative size of vascular network (c) of islets on days $0,3,6,10$ and 14 after transplantation into the dorsal skinfold chamber of $\mathrm{FVB} / \mathrm{N}$ mice, which were treated with vehicle (ctrl, white bars, $n=9$ ), DPO low dose (gray bars, $n=9$ ) or DPO high dose (black bars, $n=9$ ). Mean \pm SEM. ${ }^{a} P<0.05$ versus day 0 in each individual group; ${ }^{\mathrm{b}} P<0.05$ versus days 0 and 3 in each individual group; ${ }^{\mathrm{c}} P<0.05$ versus days 0,3 and 6 in each individual group; ${ }^{\mathrm{d}} P<0.05$ versus days $0,3,6$ and 10 in each individual group 
extravasated rhodamine 6G (Fig. 3a). DPO low-dose- and high-dose-treated animals showed a slightly, but not significantly increased endocrine tissue perfusion over the end of the observation period when compared to controls (Fig. 3a, b). Furthermore the take rate of transplanted islets on day 14 was higher in DPO low-dose $(93 \pm 5 \%)$ and DPO high-dose ( $88 \pm 6 \%)$-treated animals when compared to that of vehicle-treated controls $(79 \pm 7 \%)$. However, the statistical analysis could not confirm a significant difference.
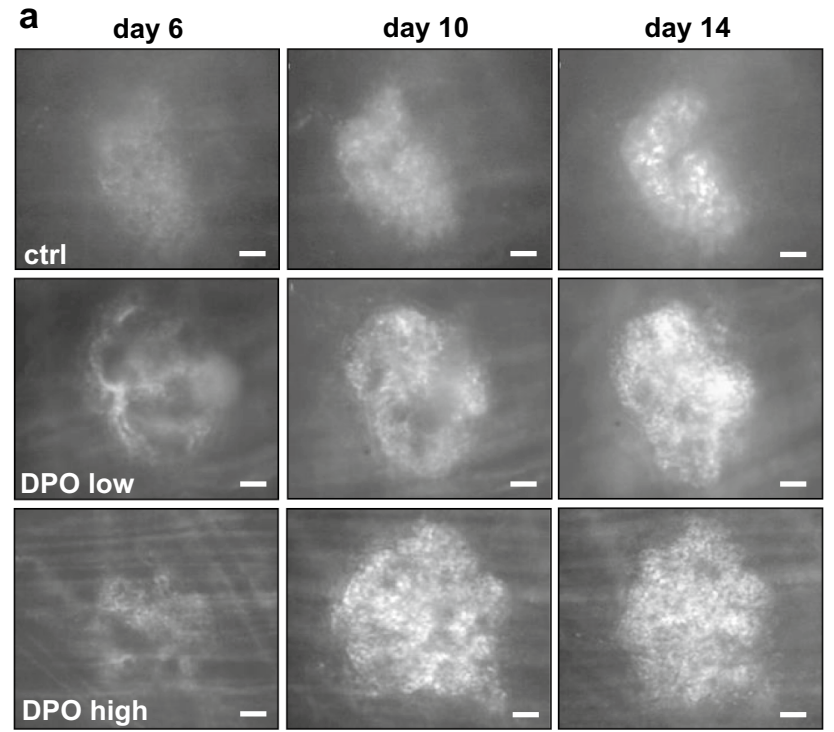

b

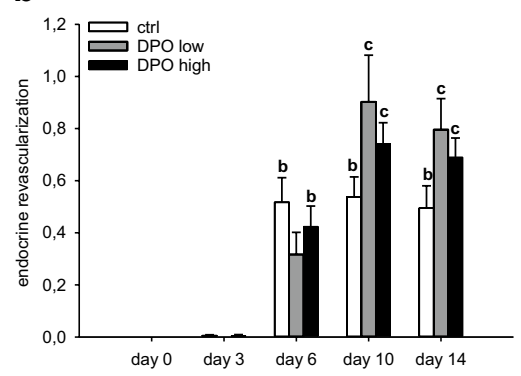

Fig. 3 Effect of DPO treatment on the endocrine tissue perfusion of transplanted islets. a Representative intravital microscopic images of islets on days 6,10 and 14 after transplantation into the dorsal skinfold chamber of $\mathrm{FVB} / \mathrm{N}$ mice, which were treated with vehicle (ctrl), DPO low dose or DPO high dose. Rhodamine $6 \mathrm{G}$ was used to visualize the endocrine tissue perfusion (revascularization) in green light epi-illumination Scale bar: $50 \mu \mathrm{m}$. b Endocrine revascularization of islets on days $0,3,6,10$ and 14 after transplantation into the dorsal skinfold chamber of $\mathrm{FVB} / \mathrm{N}$ mice, which were treated with vehicle (ctrl, white bars, $n=9$ ), DPO low dose (gray bars, $n=9$ ) and DPO high dose (black bars, $n=9$ ). Mean \pm SEM. ${ }^{\mathrm{b}} P<0.05$ versus days 0 and 3 in each individual group; ${ }^{c} P<0.05$ versus days 0,3 and 6 in each individual group

\section{Effect of DPO on the microhemodynamic parameters of the islet grafts}

The diameters, centerline RBC velocity and, accordingly, the volume flow of newly formed microvessels within the transplanted islets of the three groups were determined. The diameter of the microvessels was not affected by DPO lowdose treatment; however, DPO high-dose treatment enlarged the vessel diameter on day 14 (Fig. 4a-d). The centerline RBC velocity did not differ between the experimental groups throughout the entire observation period (Fig. 4e). This resulted in a significantly increased blood volume flow in DPO high-dose-treated animals when compared to vehicletreated and low-dose-treated mice (Fig. 4f).

\section{Histological and immunohistochemical analysis of the islet grafts}

On day 14 the HE-stainings revealed an intact morphology of transplanted islets in all three study groups (Fig. 5a). It has been shown that DPO reduces inflammation-induced tissue injury $[9,17]$. Therefore, we analyzed the number of MPOpositive neutrophilic granulocytes and monocytes infiltrating the grafts. We did not detect any MPO-positive cells within transplanted islets of the different groups (Fig. 5b). Moreover, we did not measure any cleaved caspase-3-positive cell within the grafts indicating a lack of apoptotic cell death (data not shown).

We next assessed the number of blood vessels within the grafts by means of insulin and CD31 co-staining (Fig. 5c-e). DPO treatment affects neither the number of insulin-positive cells nor the formation of new blood vessels within the grafts. In addition, we analyzed the effect of DPO on fate of intra-islet endothelial cells by co-staining of GFP and CD31 (Fig. 5f). The analyses revealed that DPO did not alter the percentage of GFP-positive donor endothelial cells.

\section{Effect of DPO on the hematopoiesis of the recipient animals}

Blood samples of the recipient animals were collected on day 14 after transplantation. The analysis revealed that the glycoprotein does not affect the number of circulating neutrophilic granulocytes and monocytes when compared to vehicle-treated controls (Table 1). DPO low-dose treatment had no significant effect on the blood values of recipient animals when compared to controls. DPO high-dose treatment, however, triggered hematopoiesis and caused a significant increase in the systemic hematocrit, hemoglobin and RBC count when compared to DPO low-dose-treated animals and vehicle-treated controls (Table 1). 
Fig. 4 Effect of DPO on the microhemodynamics of transplanted islets. a-c Representative intravital microscopic images of islets on day 14 after transplantation into the dorsal skinfold chamber of FVB/N mice, which were treated with vehicle (ctrl, a), DPD low dose (b) or DPO high dose (c). The plasma marker FITC-dextran was used for the visualization of microvessels in blue light epi-illumination. Arrows $=$ draining venules within the microvascular network. Scale bar: $50 \mu \mathrm{m}$. d-f Diameter $(\mu \mathrm{m})(\mathbf{d})$, centerline RBC velocity $(\mu \mathrm{m} / \mathrm{s})(\mathbf{e})$ and volume flow $(\mathrm{pL} / \mathrm{s})(\mathbf{f})$ of islets on days 3, 6, 10 and 14 after transplantation into the dorsal skinfold chamber of FVB/N mice, which were treated with vehicle (ctrl, white bars, $n=9$ ), DPO low (gray bars, $n=9$ ) and DPO high (black bars, $n=9$ ). Mean \pm SEM. ${ }^{a} P<0.05$ versus day 0 in each individual group; ${ }^{\mathrm{b}} P<0.05$ versus days 0 and 3 in each individual group; ${ }^{\mathrm{c}} P<0.05$ versus days 0,3 and 6 in each individual group; $* P<0.05$ versus ctrl; ${ }^{\#} P<0.05$ versus DPO low

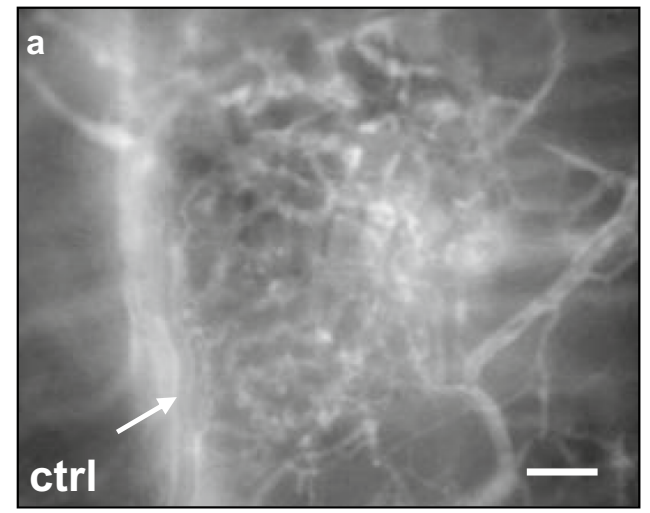

d
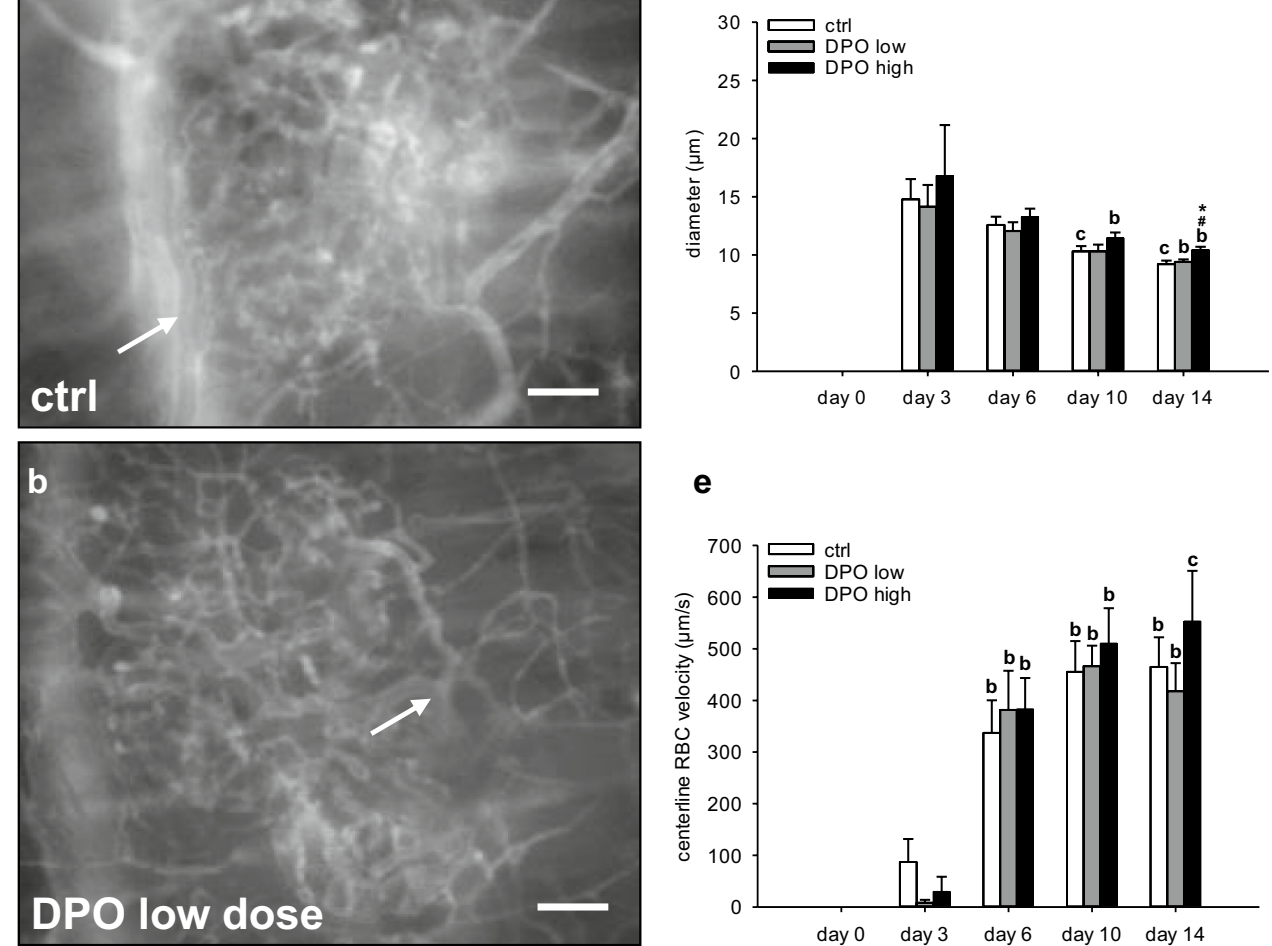

e

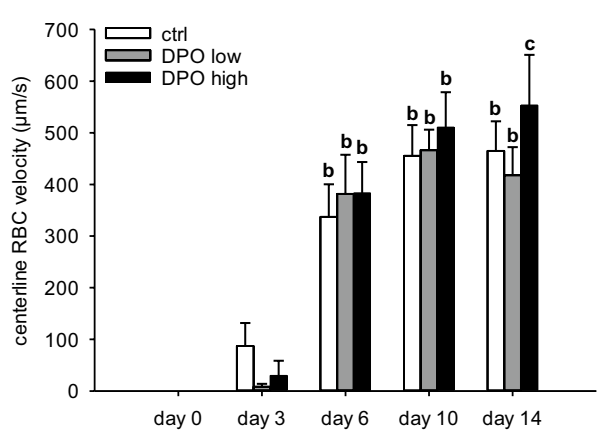

f
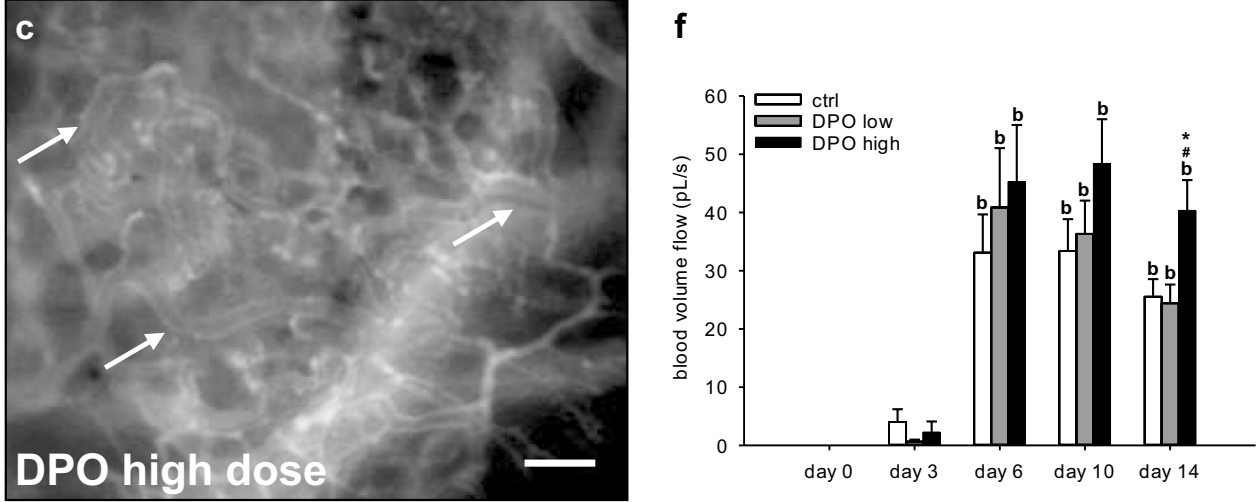

\section{Discussion}

The aim of the present study was to analyze the effects of the long lasting EPO analogue DPO on the revascularization of transplanted pancreatic islets. Our results show that DPO is not capable of accelerating the process of revascularization. However, DPO high-dose treatment increases the blood volume flow in transplanted islets. This beneficial effect was associated with significantly elevated systemic hematocrit levels in the recipient animals.

Following the enzymatic isolation procedure, pancreatic islets are completely avascular [18]. After the transplantation of freshly isolated islets, it requires 10-14 days until the new microvascular network of the grafts is fully developed [19]. This, in turn, leads to an initial shortage of oxygen and nutrients in the islet core, especially in larger islets with diameters larger than $200 \mu \mathrm{m}$ [20]. Insufficient graft revascularization during the first days after transplantation is thought to be the major reason for the poor results in clinical islet transplantation and the necessity for multiple donor pancreata to achieve normoglycemia [21].

Previous studies focused on the cultivation of islets in the presence of pro-angiogenic factors or glucagon-like peptide (GLP)-1 analoga, such as exendin-4 or liraglutide to improve the revascularization process [22-24]. Considering the fact that the culture of isolated islets impairs the function and survival of the grafts [25,26], it remains questionable if this strategy is superior to freshly transplanted islets. A different approach, proposed by Johansson et al. [27], uses tissue engineering to improve the revascularization of pancreatic islets. These authors, among others, could reveal that the co-cultivation and co-transplantation of mesenchymal 
Fig. 5 Immunohistochemical analysis of transplanted islets. a HE staining of transplanted islets on day 14 after transplantation into the dorsal skinfold chamber, which were treated with vehicle (ctrl), DPO low dose or DPO high dose. (Scale bar: $50 \mu \mathrm{m})$. b MPO-staining of transplanted islets on day 14 after transplantation into the dorsal skinfold chamber, which were treated with vehicle (ctrl), DPO low dose or DPO high dose. (Scale bar: $50 \mu \mathrm{m}$ ). c Immunofluorescence staining of insulin/CD31/merge and CD31/ GFP/merge within transplanted islets on day 14 after transplantation into the dorsal skinfold chamber of $\mathrm{FVB} / \mathrm{N}$ mice, which were treated with vehicle (ctrl), DPO low dose or DPO high dose. (Scale bar: $50 \mu \mathrm{m})$. d-f Quantification of insulin- (b), CD31- (c) (in \% of all islet cells) and GFP- (d) positive cells (in \% of all CD31-positive cells) within transplanted islets on day 14 after transplantation into the dorsal skinfold chamber of $\mathrm{FVB} / \mathrm{N}$ mice, which were treated with vehicle (ctrl), DPO low dose or DPO high dose $(n=9$; per group). Mean \pm SEM

\section{a}
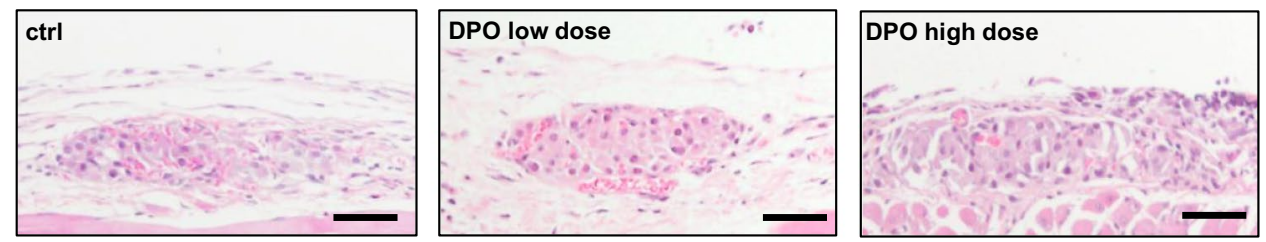

b
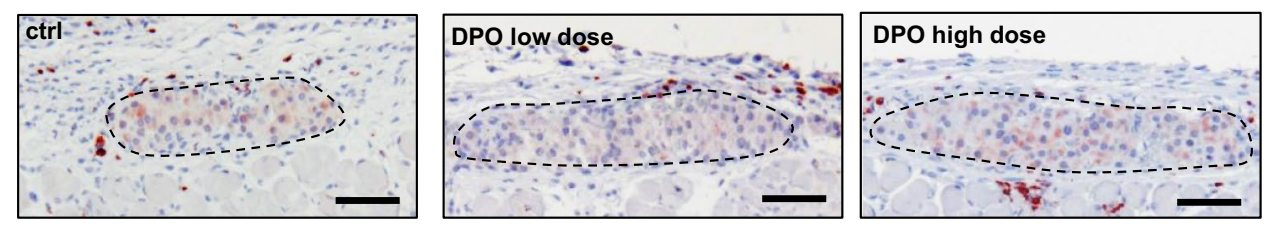

c
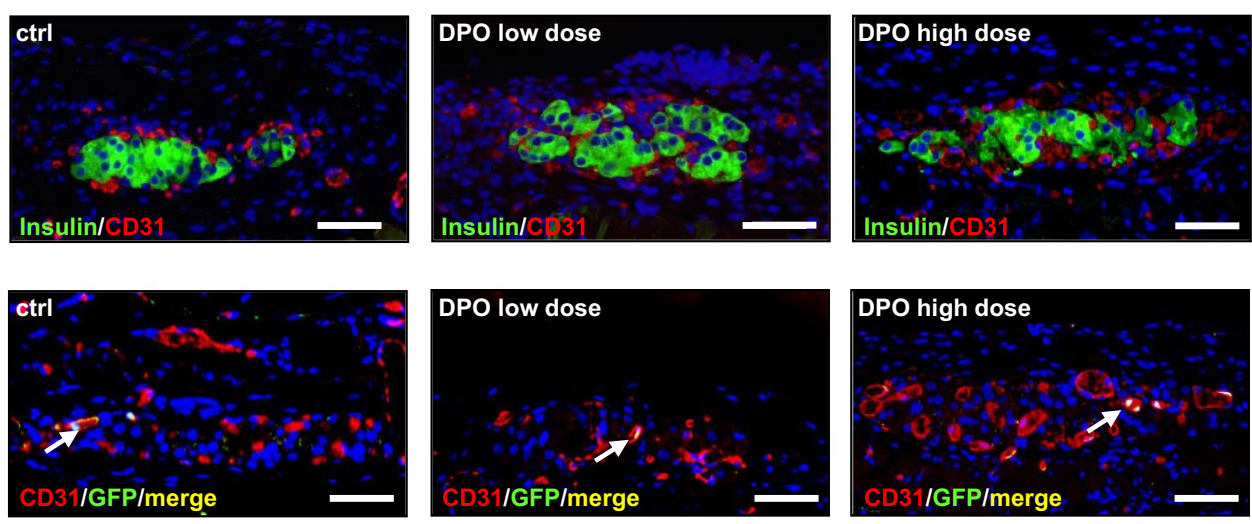

d

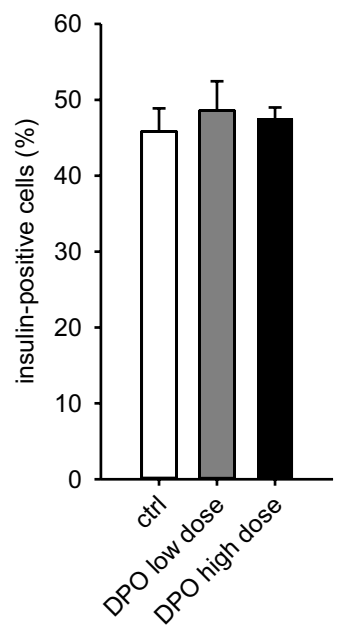

stem cells and endothelial cells with islets induce angiogenesis and therefore benefit the revascularization process $[28,29]$. However, the cultivation of multiple cell lines is hard to achieve in a clinical setting due to financial, organizational and regulatory obstacles, and, in particular, due to the risk of the contamination of the islet grafts during the e f
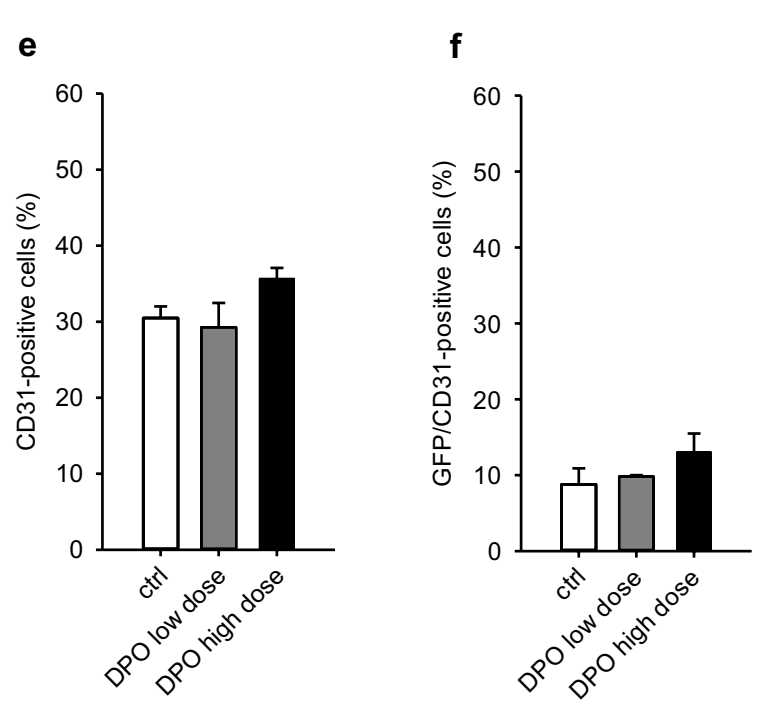

incorporation procedure. Therefore, the treatment of the recipients with pharmacological drugs, which specifically trigger angiogenic pathways, would be a more practical and viable approach.

We have recently shown that EPO is a promising compound to accelerate the revascularization process of 
Table 1 Neutrophilic granulocytes, monocytes $\left(10^{9} / \mathrm{L}\right)$, hematocrit $(\%)$, hemoglobin $(\mathrm{g} / \mathrm{dl})$ and $\mathrm{RBC}\left(10^{12} / \mathrm{L}\right)$ of the recipient animals on day 14 after transplantation, which were treated with vehicle (ctrl, $n=9)$, DPO low dose $(n=9)$ or DPO high dose $(n=9)$

\begin{tabular}{llllll}
\hline & $\begin{array}{l}\text { Neutrophilic granulo- } \\
\text { cytes }\left(10^{9} / \mathrm{L}\right)\end{array}$ & Monocytes $\left(10^{9} / \mathrm{L}\right)$ & Hematocrit $(\%)$ & Hemoglobin $(\mathrm{g} / \mathrm{dL})$ & $\mathrm{RBC}\left(10^{12} / \mathrm{L}\right)$ \\
\hline ctrl & $1.2 \pm 0.2$ & $0.27 \pm 0.04$ & $34.3 \pm 3.0$ & $10.1 \pm 1.4$ & $7.1 \pm 0.7$ \\
DPO low & $1.1 \pm 0.3$ & $0.20 \pm 0.05$ & $39.0 \pm 3.3$ & $11.7 \pm 1.4$ & $8.4 \pm 0.7$ \\
DPO high & $1.7 \pm 0.5$ & $0.15 \pm 0.09$ & $58.0 \pm 1.4^{* \#}$ & $20.5 \pm 0.5^{* \#}$ & $11.5 \pm 0.4^{* \#}$ \\
\hline
\end{tabular}

All data are mean \pm SEM. $* P<0.05$ versus ctrl; ${ }^{\#} P<0.05$ versus DPO low dose

transplanted pancreatic islets. However, the pro-angiogenic effect was predominant, when EPO was administrated prior islet transplantation [30]. This pretreatment might not be possible to transfer in a clinical setting, as the transplantation process is a swift procedure with little time between receiving the donor organ and the transplantation itself.

The glycoprotein DPO, a long lasting analogue of EPO, which is commonly used in the treatment of anemia [31], exceeds its hematopoetic functions and is also capable of promoting angiogenesis [32]. The prolonged half-life of DPO results in a greater biological activity when compared to EPO [5]. Hence, we speculated that DPO treatment starting at the day of transplantation, could enhance the vascularization of the islet grafts. We chose $2.5 \mu \mathrm{g} / \mathrm{kg}$ DPO as low dose, which corresponds to the peptide mass of $500 \mathrm{UI} /$ $\mathrm{kg}$ EPO [6] used in our previous work and $10 \mu \mathrm{g} / \mathrm{kg}$ DPO as high dose to fully exploit the pro-angiogenic effect of the glycoprotein. Our results showed an increasing graft revascularization from the day of transplantation until day 10 after transplantation in DPO-treated and vehicle-treated animals. However, between day 10 and 14 we could not detect any further vascularization. These findings could be explained by the fact that during the first days of transplantation, proangiogenic factors produced by transplanted islet cells such as vascular endothelial growth factor (VEGF)-A stimulate and recruit endothelial cells to form new blood vessels [33, 34]. After establishment of a preliminary vessel network at day 10, vascular remodeling is necessary to form mature, fully functional blood vessels [35]. The process of remodeling it typically associated with some decrease in vessel density [36]. This, in turn, could be responsible for the slightly reduced endocrine revascularization from day 10 to day 14 , since only islet cells connected to perfused blood vessels can be stained with rhodamine $6 \mathrm{G}$.

Unfortunately, both the DPO low-dose and the DPO highdose treatment failed to accelerate the process of revascularization, as indicated by a similar functional capillary density between the 3 experimental groups throughout the observation period. In fact, the DPO low-dose treatment showed an even lower angiogenic response when compared to the EPO treatment performed in our previous study [30]. Furthermore, the relative size of the vascular network and the endocrine revascularization did not differ between the three experimental groups. However, the DPO high-dose treatment increased the blood volume flow in the transplanted islets. This might be due to a vasodilatory effect of DPO, which is caused by an enhanced expression of eNOS, leading to a higher level of NO [37]. We observed a similar vasodilatory effect of EPO on the blood vessels of the dorsal skinfold chamber tissue [30]. Anneren et al. [38] demonstrated that a reduced insulin secretion accompanies a decreased blood flow in transplanted islets. Therefore, it can be assumed that the increased blood volume flow, observed in DPO high-dose-treated animals, also improves the grafts endocrine function.

As expected, the cellular composition of the transplanted islets was not affected by DPO treatment. We observed no differences in the ratio of insulin- and CD31-positive islet cells between the study groups. The Tie-2/GFP-positive donor mice allowed additional analysis of the origin of intraislet endothelial cells. Our results revealed that donor islet endothelial cells only contributed to $9-13 \%$ to the islet vasculature. This is in line with previous studies, demonstrating that the revascularization of transplanted islets is caused by recipient endothelial cells of host origin with an only lesser role of donor islet endothelial cells [18, 39, 40].

DPO stimulates erythropoiesis and thereby increases RBC count, hemoglobin and hematocrit levels [41, 42]. In the present study, the analysis of blood samples on day 14 revealed that only DPO high-dose treatment significantly enhances the red blood cell count, hemoglobin and hematocrit levels compared to both the DPO low dose and the control group. There is evidence that this hematopoietic effect of DPO is entailed to a higher risk of thromboembolic events [43-45]. In contrast, Lindenblatt et al. [37] could demonstrate that DPO-stimulated erythropoiesis is not necessarily associated with an elevated risk of thrombus formation, as long as NO production serves as protective mechanism. Still, the effects of raised hematocrit levels induced by ESAs require further investigation, before the carefree application in a clinical setting can be considered.

Most of the current concepts to improve the revascularization of transplanted islets are based on tissue engineering approaches [46-48] rather than pharmacology strategies [30, 
49]. We herein found that DPO treatment does not accelerate the revascularization process of transplanted pancreatic islets. However, the glycoprotein increases the blood volume flow of the grafts resulting in an improved microvascular function. Thus, our results may indicate that DPO treatment could improve the transplantation and the outcome of tissue-engineered islets, i.e. islets which were prevascularized before transplantation [50-52]. In addition, although our data show that DPO does not improve revascularization and engraftment, its increase in microvascular blood volume flow may have the potential to improve the function of successfully revascularized islets at later time points after transplantation.

Acknowledgements We are grateful for the excellent technical assistance of Caroline Bickelmann.

Funding Open Access funding enabled and organized by Projekt DEAL.

\section{Compliance with ethical standards}

Conflict of interest The authors declare that they have no conflict of interest.

Ethical standard All experiments were performed according to the German legislation on protection of animals and the National Institutes of Health (NIH) Guide for the Care and Use of Laboratory Animals (Institute of Laboratory Animal Resources, National Research Council, Washington DC, USA). The local governmental animal protection committee approved them.

Informed consent For this type of study informed consent is not required.

Open Access This article is licensed under a Creative Commons Attribution-NonCommercial 4.0 International License, which permits any non-commercial use, sharing, adaptation, distribution and reproduction in any medium or format, as long as you give appropriate credit to the original author(s) and the source, provide a link to the Creative Commons licence, and indicate if changes were made. The images or other third party material in this article are included in the article's Creative Commons licence, unless indicated otherwise in a credit line to the material. If material is not included in the article's Creative Commons licence and your intended use is not permitted by statutory regulation or exceeds the permitted use, you will need to obtain permission directly from the copyright holder. To view a copy of this licence, visit http://creativecommons.org/licenses/by-nc/4.0/.

\section{References}

1. Ryan EA, Shandro T, Green K et al (2004) Assessment of the severity of hypoglycemia and glycemic lability in type 1 diabetic subjects undergoing islet transplantation. Diabetes 53(4):955-962

2. Schramm R, Yamauchi J, Vollmar B, Vajkoczy P, Menger MD (2003) Blockade of in vivo VEGF-KDR/flk-1 signaling does not affect revascularization of freely transplanted pancreatic islets. Transplantation 75(2):239-242. https://doi.org/10.1097/01.TP. $0000040869.19883 .4 \mathrm{~A}$
3. Ahearn AJ, Parekh JR, Posselt AM (2015) Islet transplantation for type 1 diabetes: Where are we now? Expert Rev Clin Immunol 11(1):59-68. https://doi.org/10.1586/1744666X.2015.978291

4. Menger MM, Nalbach L, Roma LP et al (2019) Erythropoietin accelerates the revascularization of transplanted pancreatic islets. Br J Pharmacol. https://doi.org/10.1111/bph.14925

5. Hörl WH (2013) Differentiating factors between erythropoiesisstimulating agents: an update to selection for anaemia of chronic kidney disease. Drugs 73(2):117-130. https://doi.org/10.1007/ s40265-012-0002-2

6. Jelkmann W (2013) Physiology and pharmacology of erythropoietin. Transfus Med Hemotherapy Off Organ Deutschen Ges Transfus Med Immunhamatol 40(5):302-309. https://doi.org/10. $1159 / 000356193$

7. Allon M, Kleinman K, Walczyk M et al (2002) Pharmacokinetics and pharmacodynamics of darbepoetin alfa and epoetin in patients undergoing dialysis. Clin Pharmacol Ther 72(5):546-555. https:// doi.org/10.1067/mcp.2002.128374

8. Johnson DW, Pat B, Vesey DA, Guan Z, Endre Z, Gobe GC (2006) Delayed administration of darbepoetin or erythropoietin protects against ischemic acute renal injury and failure. Kidney Int 69(10):1806-1813. https://doi.org/10.1038/sj.ki.5000356

9. Le Minh K, Klemm K, Abshagen K, Eipel C, Menger MD, Vollmar B (2007) Attenuation of inflammation and apoptosis by preand posttreatment of darbepoetin-alpha in acute liver failure of mice. Am J Pathol 170(6):1954-1963

10. Broberg AM, Grinnemo KH, Genead R et al (2008) Erythropoietin has an antiapoptotic effect after myocardial infarction and stimulates in vitro aortic ring sprouting. Biochem Biophys Res Commun 371(1):75-78. https://doi.org/10.1016/j.bbrc.2008.04. 025

11. Rupertus K, Senger S, Menger MD, Schilling MK, Kollmar O (2012) Darbepoetin-alpha promotes neovascularization and cell proliferation in established colorectal liver metastases. J Surg Res 176(2):517-523. https://doi.org/10.1016/j.jss.2011.09.062

12. Gotoh M, Maki T, Satomi S et al (1987) Reproducible high yield of rat islets by stationary in vitro digestion following pancreatic ductal or portal venous collagenase injection. Transplantation 43(5):725-730

13. Laschke MW, Vollmar B, Menger MD (2011) The dorsal skinfold chamber: window into the dynamic interaction of biomaterials with their surrounding host tissue. Eur Cell Mater 22:147-164

14. Vajkoczy P, Menger MD, Simpson E, Messmer K (1995) Angiogenesis and vascularization of murine pancreatic islet isografts. Transplantation 60(2):123-127

15. Menger MD, Vajkoczy P, Leiderer R, Jager S, Messmer K (1992) Influence of experimental hyperglycemia on microvascular blood perfusion of pancreatic islet isografts. J Clin Invest 90(4):13611369. https://doi.org/10.1172/JCI116002

16. Ampofo E, Rudzitis-Auth J, Dahmke IN et al (2015) Inhibition of protein kinase CK2 suppresses tumor necrosis factor (TNF)-alphainduced leukocyte-endothelial cell interaction. Biochim Biophys Acta 1852(10 Pt A):2123-2136. https://doi.org/10.1016/j.bbadis. 2015.07.013

17. Strunk T, Hartel C, Temming P, Matzke N, Zimmer J, Schultz C (2008) Erythropoietin inhibits cytokine production of neonatal and adult leukocytes. Acta Paediatr 97(1):16-20. https://doi.org/ 10.1111/j.1651-2227.2007.00560.x

18. Nyqvist D, Kohler M, Wahlstedt H, Berggren PO (2005) Donor islet endothelial cells participate in formation of functional vessels within pancreatic islet grafts. Diabetes 54(8):2287-2293

19. Menger MD, Yamauchi J, Vollmar B (2001) Revascularization and microcirculation of freely grafted islets of Langerhans. World $\mathrm{J}$ Surg 25(4):509-515. https://doi.org/10.1007/s002680020345

20. Cui YF, Ma M, Wang GY, Han DE, Vollmar B, Menger MD (2005) Prevention of core cell damage in isolated islets of 
Langerhans by low temperature preconditioning. World J Gastroenterol 11(4):545-550

21. Wittig C, Laschke MW, Scheuer C, Menger MD (2013) Incorporation of bone marrow cells in pancreatic pseudoislets improves posttransplant vascularization and endocrine function. PLoS ONE 8(7):e69975. https://doi.org/10.1371/journal.pone.0069975

22. Olsson R, Maxhuni A, Carlsson PO (2006) Revascularization of transplanted pancreatic islets following culture with stimulators of angiogenesis. Transplantation 82(3):340-347. https://doi.org/ 10.1097/01.tp.0000229418.60236.87

23. King A, Lock J, Xu G, Bonner-Weir S, Weir GC (2005) Islet transplantation outcomes in mice are better with fresh islets and exendin-4 treatment. Diabetologia 48(10):2074-2079. https://doi. org/10.1007/s00125-005-1922-0

24. Langlois A, Mura C, Bietiger W et al (2016) In vitro and in vivo investigation of the angiogenic effects of liraglutide during islet transplantation. PLoS ONE 11(3):e0147068. https://doi.org/10. 1371/journal.pone.0147068

25. Olsson R, Carlsson PO (2005) Better vascular engraftment and function in pancreatic islets transplanted without prior culture. Diabetologia 48(3):469-476. https://doi.org/10.1007/ s00125-004-1650-x

26. Noguchi H, Naziruddin B, Jackson A et al (2012) Fresh islets are more effective for islet transplantation than cultured islets. Cell Transplant 21(2-3):517-523. https://doi.org/10.3727/09636 8911 X605439

27. Johansson U, Rasmusson I, Niclou SP et al (2008) Formation of composite endothelial cell-mesenchymal stem cell islets: a novel approach to promote islet revascularization. Diabetes 57(9):23932401. https://doi.org/10.2337/db07-0981

28. Ito T, Itakura S, Todorov I et al (2010) Mesenchymal stem cell and islet co-transplantation promotes graft revascularization and function. Transplantation 89(12):1438-1445

29. Oh BJ, Oh SH, Jin SM et al (2013) Co-transplantation of bone marrow-derived endothelial progenitor cells improves revascularization and organization in islet grafts. Am J Transplant Off J Am Soc Transplant Am Soc Transpl Surg 13(6):1429-1440. https:// doi.org/10.1111/ajt.12222

30. Menger MM, Nalbach L, Roma LP et al (2019) Erythropoietin accelerates the revascularization of transplanted pancreatic islets. Br J Pharmacol. https://doi.org/10.1111/bph.14925

31. Overbay DK, Manley HJ (2002) Darbepoetin-alpha: a review of the literature. Pharmacotherapy 22(7):889-897

32. Rupertus K, Sperling J, Corsten M et al (2010) Darbepoetin-alpha enhances hepatectomy-associated stimulation of colorectal liver metastatic growth. Ann Surg 252(1):131-141. https://doi.org/10. 1097/SLA.0b013e3181e33915

33. Lammert $\mathrm{E}, \mathrm{Gu} \mathrm{G}, \mathrm{McLaughlin} \mathrm{M}$ et al (2003) Role of VEGF-A in vascularization of pancreatic islets. Curr Biol 13(12):1070-1074. https://doi.org/10.1016/s0960-9822(03)00378-6

34. Watada H (2010) Role of VEGF-A in pancreatic beta cells. Endocr J 57(3):185-191. https://doi.org/10.1507/endocrj.k09e-035

35. Brissova M, Shostak A, Shiota M et al (2006) Pancreatic islet production of vascular endothelial growth factor-a is essential for islet vascularization, revascularization, and function. Diabetes 55(11):2974-2985. https://doi.org/10.2337/db06-0690

36. Korn C, Augustin HG (2015) Mechanisms of vessel pruning and regression. Dev Cell 34(1):5-17. https://doi.org/10.1016/j.devcel. 2015.06.004

37. Lindenblatt N, Menger MD, Klar E, Vollmar B (2007) Darbepoetin-alpha does not promote microvascular thrombus formation in mice: role of eNOS-dependent protection through platelet and endothelial cell deactivation. Arterioscler Thromb Vasc Biol 27(5):1191-1198. https://doi.org/10.1161/ATVBAHA.107. 141580
38. Anneren C, Welsh M, Jansson L (2007) Glucose intolerance and reduced islet blood flow in transgenic mice expressing the FRK tyrosine kinase under the control of the rat insulin promoter. Am J Physiol Endocrinol Metab 292(4):E1183-E1190. https://doi.org/ 10.1152/ajpendo.00168.2006

39. Henriksnas J, Lau J, Zang G, Berggren PO, Kohler M, Carlsson PO (2012) Markedly decreased blood perfusion of pancreatic islets transplanted intraportally into the liver: disruption of islet integrity necessary for islet revascularization. Diabetes 61(3):665673. https://doi.org/10.2337/db10-0895

40. Vajkoczy P, Olofsson AM, Lehr HA et al (1995) Histogenesis and ultrastructure of pancreatic islet graft microvasculature. Evidence for graft revascularization by endothelial cells of host origin. Am J Pathol 146(6):1397-1405

41. Horl WH (2013) Differentiating factors between erythropoiesisstimulating agents: an update to selection for anaemia of chronic kidney disease. Drugs 73(2):117-130. https://doi.org/10.1007/ s40265-012-0002-2

42. Alsalimy N, Awaisu A (2014) Methoxy polyethylene glycol-epoetin beta versus darbepoetin alfa for anemia in non-dialysis-dependent CKD: a systematic review. Int J Clin Pharm 36(6):1115-1125. https://doi.org/10.1007/s11096-014-0023-x

43. Wolf RF, Peng J, Friese P, Gilmore LS, Burstein SA, Dale GL (1997) Erythropoietin administration increases production and reactivity of platelets in dogs. Thromb Haemost 78(6):1505-1509

44. Beguin Y (1999) Erythropoietin and platelet production. Haematologica 84(6):541-547

45. Stohlawetz PJ, Dzirlo L, Hergovich N et al (2000) Effects of erythropoietin on platelet reactivity and thrombopoiesis in humans. Blood 95(9):2983-2989

46. Vlahos AE, Kinney SM, Kingston BR et al (2020) Endothelialized collagen based pseudo-islets enables tuneable subcutaneous diabetes therapy. Biomaterials 232:119710. https://doi.org/10.1016/j. biomaterials.2019.119710

47. Fransson M, Brannstrom J, Duprez I et al (2015) Mesenchymal stromal cells support endothelial cell interactions in an intramuscular islet transplantation model. Regen Med Res 3:1. https://doi. org/10.1186/s40340-015-0010-9

48. Song W, Chiu A, Wang LH et al (2019) Engineering transferrable microvascular meshes for subcutaneous islet transplantation. Nat Commun 10(1):4602. https://doi.org/10.1038/ s41467-019-12373-5

49. Li S, Vaziri ND, Masuda Y et al (2015) Pharmacological activation of Nrf2 pathway improves pancreatic islet isolation and transplantation. Cell Transplant 24(11):2273-2283. https://doi. org/10.3727/096368915X686210

50. Pan X, Xue W, Li Y, Feng X, Tian X, Ding C (2011) Islet graft survival and function: concomitant culture and transplantation with vascular endothelial cells in diabetic rats. Transplantation 92(11):1208-1214. https://doi.org/10.1097/TP.0b013e3182 $356 \mathrm{ca} 7$

51. Perez-Basterrechea M, Esteban MM, Alvarez-Viejo M et al (2017) Fibroblasts accelerate islet revascularization and improve longterm graft survival in a mouse model of subcutaneous islet transplantation. PLoS ONE 12(7):e0180695. https://doi.org/10.1371/ journal.pone.0180695

52. Lebreton F, Lavallard V, Bellofatto K et al (2019) Insulin-producing organoids engineered from islet and amniotic epithelial cells to treat diabetes. Nat Commun 10(1):4491. https://doi.org/ $10.1038 / \mathrm{s} 41467-019-12472-3$

Publisher's Note Springer Nature remains neutral with regard to jurisdictional claims in published maps and institutional affiliations. 